\title{
Un racconto e una lotta lunghi 10 anni
}

\author{
Luisa Sternfeld Pavia \\ Presidente Associazione Italiana del Rene Policistico AIRP onlus, Milano
}

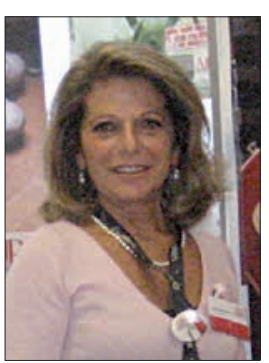

Luisa Sternfeld Pavia
"Dentro di te c'è un puntino rosso e morbido che cresce piano piano. Ce n'è anche uno bianco che qualche volta ti fa paura, ma, se guardi attentamente, ne scoprirai tanti altri e tutti di colori diversi, perché anche se fuori non si vede, ognuno di noi ha dentro di sé l'arcobaleno".

È questo un delicato passaggio del nostroraccontoperparoleeimmagini“"Dentro di me" (Fig. 1), scritto da Cosetta Zanotti e illustrato da Elena Gallina, per raccontare una malattia complessa e subdola: il rene policistico autosomico dominante (ADPKD) e la sua variante recessiva (ARPKD).

Se questo modo di comunicare la malattia, semplice e tenero, ben si addice alla comunicazione di massa diretta ai pazienti di tutte le età, ben altra e ben più impegnata sarà la comunicazione che AIRP proporrà nel suo meeting internazionale in occasione del decennale "Rene Policistico: conoscere per riconoscere, 10 anni di lotta raccontati da medici e pazienti" (Roma, 19 Settembre 2015, presso l'Istitutó Superiore di Sanità; per il programma visitare il sito www.renepolicistico.it).

Un'occasione, dunque, per fare il punto sui progressi della scienza medica e terapeutica in materia di rene policistico, una patologia fino a pochi anni fa definita "negletta", cioè quasi sconosciuta, sicuramente sottostimata e perlopiù diagnosticata tardivamente.

Nel corso di questi dieci anni, AIRP si è adoperata per svelare questo male e per renderlo palese agli occhi e alle menti, spesso pigre, di responsabili della salute e della sanità, che, di fronte ai "misteri" di una malattia genetica, faticavano (ora possiamo cominciare a parlarne al passato!) ad accettarne le

Accepted: July 6, 2015

Published online: July 29, 2015

Indirizzo per la corrispondenza:

Dr.ssa Luisa Sternfeld Pavia

AIRP Associazione Italiana Rene Policistico onlus

Via A. Bazzini 2

20131 Milano

luisa.sternfeld.airp@renepolicistico.it

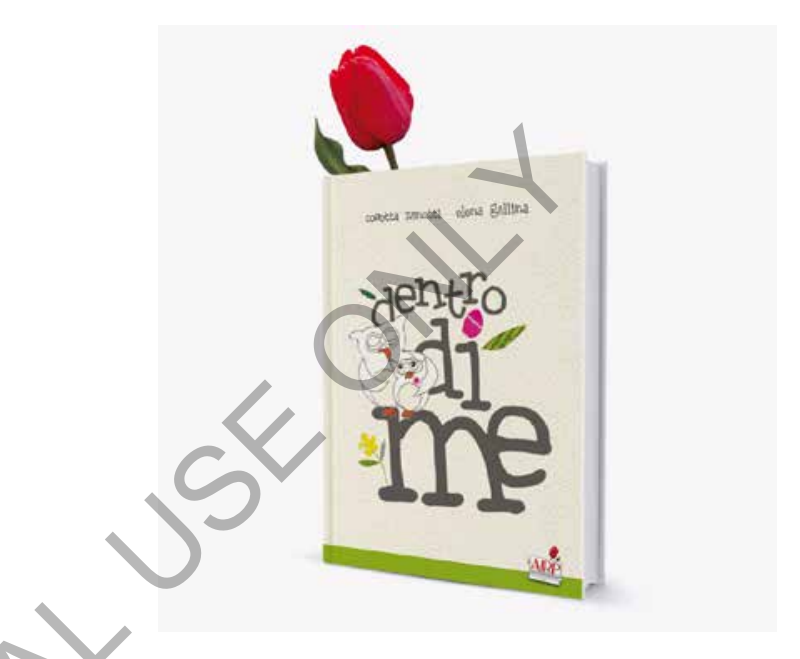

Fig. 1 - Libro "Dentro di me".

peculiarità. Perché il rene policistico, proprio per il fatto che colpisce a caso membri di nuclei familiari a causa della sua ereditarietà, determina non solo esigenze importanti di cura, ma anche risvolti psicologici e sociali rilevanti.

A Roma, il 19 Settembre, i più illustri Medici e Scienziati esperti di questa malattia illustreranno i progressi della scienza medica, in un evento in cui al centro saranno i Pazienti, con i loro diritti, le loro ansie e le loro speranze. Progressi che sono, fortunatamente, rilevanti: nuovi trattamenti si profilano all'orizzonte prossimo venturo e nuovi criteri di prevenzione e diagnosi sono stati perfezionati per favorire un'intercettazione precoce della patologia e, quindi, una scelta appropriata delle migliori terapie.

Il simposio internazionale romano, ce lo auguriamo di tutto cuore, potrà essere un tornante, una curva di una strada in discesa verso terapie sempre più avanzate e decisive, in grado, un domani speriamo non troppo lontano, di sconfiggere il rene policistico.

AIRP, superata la boa del decennio, si avvia verso una nuova stagione di impegno, con ottimismo e determinazione, ma ha bisogno dell'aiuto di tutti voi!

Buon decennale a tutti e buona estate! 